\title{
Comparison of coronary arterial lumen dimensions on angiography and plaque characteristics on optical coherence tomography images and their changes induced by statin
}

\author{
Nana Dong ${ }^{1,2}$, Zulong Xie', Wei Wang ${ }^{1}$, Jiannan Dai ${ }^{1}$, Meng Sun ${ }^{2}$, Zhongyue Pu', Jinwei Tian ${ }^{1 *}$ and Bo Yu ${ }^{1,2^{*}}$
}

\begin{abstract}
Background: Coronary angiography (CAG) is widely used to assess lumen dimensions, and optical coherence tomography $(\mathrm{OCT})$ is used to evaluate the characteristics of atherosclerotic plaque. This study was aimed to compare coronary lumen dimensions using CAG and plaque characteristics using OCT and their changes during statin therapy.

Methods: We identified 97 lipid-rich plaques from 69 statin-naïve patients, who received statin therapy in the following 12 months. CAG and OCT examinations were conducted at baseline and 12-month follow-up period.

Results: Lesion length, as measured by CAG, was closely correlated with lipid length by OCT (baseline: $r=0.754$, $p<0.001$; follow-up: $r=0.639, p<0.001$ ). However, no significant correlations were found between the other findings on OCT and data on CAG. With 12-month statin therapy, microstructures of lipid-rich plaques were significantly improved, but CAG-derived lumen dimensions were not improved. Moreover, we found no significant relationship between changes in OCT measurements and changes in CAG data over time.
\end{abstract}

Conclusion: Lipid length on OCT and lesion length on CAG were closely correlated. However, plaque microstructural characteristics on OCT showed no significantly statistically correlations with lumen dimensions on $C A G$, neither did their evolutionary changes induced by statin over time.

A retrospectively registered study: Clinical trial registry: ClinicalTrial.gov. Registered number: NCT01023607. Registered 1 December 2009.

Keywords: Optical coherence tomography, Coronary angiography, Atherosclerosis, Statin

\section{Background}

Patients with rupture-prone lesions in the coronary arteries, also known as "vulnerable plaques", are at risk of acute coronary syndrome (ACS) [1, 2]. Morphological characteristics of vulnerable plaques tend to possess a large lipid core and a thin fibrous cap overlying inflammatory-cell infiltration [3, 4]. Statin-based lipidmodulating therapy has been documented to stabilize

\footnotetext{
* Correspondence: Tianjinweidr2009@163.com; dryu_hmu@163.com 1 Department of Cardiology, 2nd Affiliated Hospital of Harbin Medical University, 246 Xuefu Road, Nangang District, Harbin 150086, China Full list of author information is available at the end of the article
}

vulnerable plaque and reduce atheroma volume [5-7]. Catheter-based diagnostic techniques, such as coronary angiography (CAG), optical coherence tomography (OCT) and intravascular ultrasound (IVUS), provide more accurate histopathological characteristics of coronary lesions and are widely applied in clinical examination of coronary arteries before or after percutaneous coronary interventions and as adjunctive devices to assess lesion characteristics or lumen and stent situations in detail [8-10]. OCT, with a high resolution of approximately $10-20 \mu \mathrm{m}$, allows for the assessment of the microstructures in plaques and has recently been regarded 
as an "optical biopsy" imaging modality that can visualize the morphological characteristics and compositions of plaques in situ and in real time [4, 11-13]. It is generally known that CAG is widely used to assess lumen dimensions, and display the lumen as a longitudinal and cross-sectional silhouette [14-16]. The current study was aimed to identify the relationship between lumen dimensions as seen on CAG and plaque microstructures as seen on OCT, and the relationship between their changes during statin intervention.

\section{Methods}

\section{Study population}

This was a retrospective study of a single blind and randomized clinical trial registry (ClinicalTrial.gov registered number: NCT01023607), designed to assess the effects of statins on lipid-rich plaques. The inclusion criteria were as follows: 1) were statin-naïve (i.e., those who were not on statins) patients with one or more mild-to-moderate lesion(s); 2) had non-culprit lesions identified as lipid-rich plaques by OCT; 3 ) were to receive statin treatment during the following 12-month follow-up period; and 4) were to undergo CAG and three-vessel OCT imaging procedures during the 12-month follow-up period. The exclusion criteria were as follows: 1) a life expectancy $\leq 12$ months; 2 ) contraindications to oral statins; 3 ) severe hepatic or renal dysfunction; or 4) congestive heart failure. Fifty-one patients including those who didn't have the follow-up information $(n=31)$, had poor-quality images from OCTs $(n=13)$, and mismatched imaging $(n=7)$ were excluded. After screening, 69 patients (62.3\% male; age: $55.7 \pm 9.4$ years) with 97 coronary non-culprit, lipidrich plaques (30.1\% located in the left anterior descending artery, $46.6 \%$ in right coronary artery, $17.5 \%$ in left circumflex artery) were analyzed in the current study. This study was approved by the institutional review board of the Second Hospital of Harbin Medical University (Harbin, China), and all patients provided written informed consent before any procedures were initiated.

\section{Angiographic and OCT images follow-up}

According to the study protocol, follow-up angiography and three-vessel OCT images were performed at baseline and 12 months. Quantitative angiographic of the coronary arteries was performed to determine the minimal lumen diameter (MLD), diameter stenosis (DS) and lesion length as previously described in detail [17]. The interpreter was blinded to OCT findings. Analyses of the baseline and follow-up coronary angiograms were conducted using the Cardiovascular Angiography Analysis System (CAAS 5.10, Pie Medical Imaging B.V., Maastricht, the Netherlands).

After detecting by CAG and dealing with the culprit/target lesions, intracoronary OCT images were performed as previously described $[4,5]$. In short, with the TD OCT system, a 3-F occlusion balloon catheter was advanced proximal to the lesion and inflated at $0.5 \mathrm{~atm}$. to $0.7 \mathrm{~atm}$. During image acquisition, lactate Ringer's solution was infused intra-coronary from the distal tip of the occlusion balloon catheter at $0.5 \mathrm{ml} / \mathrm{s}$ to $2.0 \mathrm{ml} / \mathrm{s}$ by a high-pressure injector. The OCT wire was pulled back from a distal to a proximal position automatically at a rate of $1.0 \mathrm{~mm} / \mathrm{s}$. The fibrous-cap thickness (FCT) was measured 3 times at the thinnest place, and the values were averaged. A lipid-rich plaque was defined as previously that plaque with fibrouscap thickness $<120 \mu \mathrm{m}$ and lipid $\operatorname{arc}>100^{\circ}$ [5]. In lipidrich plaque, the lipid arc was measured at $1 \mathrm{~mm}$ interval, the maximum value was recorded as maximum lipid arc, and the mean value was calculated as mean lipid arc. Lipid length was measured on a longitudinal view. Lipid index, was calculated as the mean lipid arc multiplied by lipid length [18]. A thin-cap fibroatheroma (TCFA) has rich lipid core and FCT $<65 \mu \mathrm{m}$, while a thick-cap fibroatheroma (ThCFA) was a LRP with a thick fibrous cap $(\geq 65 \mu \mathrm{m})[3,19]$. Macrophage accumulation was characterized as increased signal intensity, combined with heterogeneous backward shadows within the lesion. Microvessel, also named neovascularization, appears as signal-free tubuloluminal structure with a diameter of 50-300 $\mu \mathrm{m}$ that was observed as $\geq 3$ consecutive cross-sectional OCT images [20]. Beside lipid pool, the thin and linear region of high intensity was cholesterol crystal [21]. Intraluminal thrombus was identified as protruding masses attached to the arterial wall [22]. Calcification was recorded when an area showed low backscatter signal and a sharply delineated border. Plaque disruption was a discontinued fibrous membrane with underlying communication between the lumen and the cavity.

All OCT images were analyzed using proprietary offline software (LightLab Imaging, Inc., Westford, MA, USA) by two independent, experienced observers. In cases in which was disagreement between them, a third independent investigator helped reach a consensus on image matching and quality. All investigators of CAG and OCT images were blinded to the patient's conditions and the study protocol, and all images were digitally stored for future analyses. In the follow up studies, repeated measurements from the same reference points were performed, and the measurements of CAG and OCT between the two points were determined using computer software.

\section{Statistical analysis}

All statistical analysis was performed by an independent statistician using IBM SPSS version 17.0 (SPSS Inc., Chicago, Illinois, USA). Data are expressed as mean \pm standard deviation (SD) or counts and proportions. Quantitative data at baseline and at follow-up are compared using paired $t$ test and qualitative data using McNemar test. Continuous 
variables between TCFAs and ThCFAs were compared by using unpaired $t$ test. The categorical variables were analyzed using the Chi-square or Fisher exact test. Pearson or Spearman ranks test was used to investigate the relationship between CAG findings and OCT measurements, and also the correlations between changes in CAG and changes in OCT measurements. A $p$-value $<0.05$ was considered to be statistically significant.

\section{Results}

The baseline clinical characteristics of the patients are shown in Table 1. As shown in Table 2, with statin treatment, the level of low-density lipoprotein cholesterol (LDLC) was decreased by $25.4 \%$ (from $109.4 \pm 24.6 \mathrm{mg} / \mathrm{dL}$ baseline to $73.9 \pm 29.2 \mathrm{mg} / \mathrm{dL}$ follow-up, $p<0.001$ ). In addition, except for high-density lipoprotein cholesterol (HDL-C), the total cholesterol, triglycerides, and apolipoprotein $\mathrm{B}$ were all markedly improved ( $p<0.001, p<0.001, p<0.001, p=$ 0.005 , respectively).

The lesion measurements done using CAG and OCT at baseline and follow-up are shown in Table 2. With statin

Table 1 Baseline clinical characteristics

\begin{tabular}{ll}
\hline Baseline characteristics & \\
\hline Patients number & $n=69$ \\
Age, years & $55.7 \pm 9.4$ \\
Male & $43(62.3)$ \\
Hypertension & $44(63.8)$ \\
Diabetes & $34(49.3)$ \\
Smoking & $33(47.8)$ \\
Previous MI & $15(21.7)$ \\
Prior PCl & $12(17.4)$ \\
ACS & $55(79.7)$ \\
SAP & $14(20.3)$ \\
Concomitant drugs at follow-up: & \\
ACEI/ARB & $31(44.9)$ \\
Beta blocker & $42(60.9)$ \\
CCB & $19(27.5)$ \\
Aspirin & $68(98.6)$ \\
Clopidogrel & $68(98.6)$ \\
Nitrate & $40(60.0)$ \\
Angiographic Findings: & \\
Plaques numbers & \\
Left Anterior Descending & \\
Right Coronary Artery & $31(30.1)$ \\
Left Circumflex & $48(46.6)$ \\
\hline Data were presented as mean \pm standard deviation (SD) or number \\
for SD. ACEl angiotensin-converting enzyme inhibitor, ACS acute coronary \\
syndrome, ARB angiotensin II receptor blocker, CCB calcium channel blocker, \\
SAP stable angina pectoris, Previous MI, previous myocardial infarction, Prior \\
PCl prior percutaneous coronary intervention & \\
& \\
&
\end{tabular}

therapy for 12 months, fibrous-cap thickness increased from $61.1 \pm 18.5 \mu \mathrm{m}$ to $159.1 \pm 78.9 \mu \mathrm{m}(p<0.001)$; maximum lipid arc, mean lipid arc and lipid index significantly decreased $(p<0.001$, all). In addition, we found that lesion length on CAG slightly increased (from $11.3 \pm 5.1 \mathrm{~mm}$ baseline to $11.7 \pm 5.0 \mathrm{~mm}$ follow-up, $p=0.069$ ), but OCT showed that lipid length significantly decreased (from $9.9 \pm$ $4.7 \mathrm{~mm}$ to $9.3 \pm 4.9 \mathrm{~mm}, p=0.01$ ). Moreover, the OCT qualitative measurements showed that the prevalence of TCFA, macrophage infiltration, microvessels, and cholesterol crystals were significantly reduced at follow-up ( $p<0.001, p=0.048, p=0.022, p=0.031$, $p=0.015$, and $p=0.003$, respectively), with the exception of the presence of calcification $(p=0.868)$. However, lumen dimensions as measured by CAG, including minimal lumen diameter and diameter stenosis (MLD: from baseline $2.0 \pm 0.5 \mathrm{~mm}$ to follow-up $2.0 \pm$ $0.5 \mathrm{~mm}, p=0.824$; DS: from $28.9 \pm 10.5 \%$ to $29.5 \pm 11.1$, $p=0.53$ ), were not significantly improved.

The correlations between the CAG and OCT findings of coronary lipid-rich plaques at baseline and also at follow-up were summarized in Table 3. The lesion longitudinal silhouette data showed that the whole length of plaque (lesion length) on CAG and the length of lipid pool on OCT were closely related at any single time points $(r=0.754, p<0.001$ at baseline; $r=$ $0.639, p<0.001$ at follow-up); the lesion length also positively correlated with the lipid index. Moreover, diameter stenosis on CAG was significantly correlated with maximum lipid arc on OCT at baseline only ( $r=$ $0.209, p=0.041$ ). Minimal lumen diameter was not found significantly correlated with OCT measurements at any single time points.

As shown in Table 4, the correlations between the changes in CAG and changes in OCT quantitative data from baseline to follow-up were analyzed. Change in minimal lumen diameter from baseline to follow-up was not significantly correlated with any changes in OCT quantitative data; neither was the change in diameter stenosis. And no significant correlations were found between change in lesion length on CAG and change in lipid length on OCT.

According to the FCT at baseline, plaques were classified into TCFAs (thin-cap fibroatheromas, fibrous-cap thickness $<65 \mu \mathrm{m}$ ) and ThCFAs (thick-cap fibroatheromas, fibrous-cap thickness $\geq 65 \mu \mathrm{m})$. Comparisons of lesion characteristics between TCFAs and ThCFAs were summarized in Table 5. Fibrous-cap thickness in both groups markedly increased ( $p<0.001$ both); and the maximum lipid arc of TCFAs, but not that of ThCFAs, significantly decreased over time. Diameter stenosis of TCFAs had a mean increase of $3.86 \%(p=0.014)$ from the baseline to the 12-month follow-up; while DS of ThCFAs had a mean decrease of $1.14 \%(p=0.26)$ over 
Table 2 Serum lipid results, CAG and OCT measurements at baseline and follow-up

\begin{tabular}{|c|c|c|c|}
\hline Variables & Baseline & Follow-up & $p$-value \\
\hline \multicolumn{4}{|l|}{ Serum lipid } \\
\hline Total cholesterol, mg/dl & $198.6 \pm 42.2$ & $146.1 \pm 40.0$ & $<0.001$ \\
\hline $\mathrm{LDL}-\mathrm{C}, \mathrm{mg} / \mathrm{dl}$ & $109.4 \pm 24.6$ & $73.9 \pm 29.2$ & $<0.001$ \\
\hline $\mathrm{HDL}-\mathrm{C}, \mathrm{mg} / \mathrm{dl}$ & $49.3 \pm 12.3$ & $46.7 \pm 13.9$ & 0.123 \\
\hline LDL-C/HDL-C & $2.3 \pm 0.8$ & $1.7 \pm 0.7$ & $<0.001$ \\
\hline Triglycerides, mg/dl & $215.7 \pm 151.7$ & $140.2 \pm 64.3$ & $<0.001$ \\
\hline Apolipoprotein B, mg/dl & $89.0 \pm 24.1$ & $63.3 \pm 25.2$ & $<0.001$ \\
\hline \multicolumn{4}{|l|}{ OCT quantitative data } \\
\hline Fibrous-cap thickness, $\mu \mathrm{m}$ & $61.1 \pm 18.5$ & $159.1 \pm 78.9$ & $<0.001$ \\
\hline Maximum lipid arc, ${ }^{\circ}$ & $241.2 \pm 69.9$ & $206.4 \pm 75.3$ & $<0.001$ \\
\hline Mean lipid arc, ${ }^{\circ}$ & $174.8 \pm 51.6$ & $152.5 \pm 55.7$ & $<0.001$ \\
\hline Lipid length, mm & $9.9 \pm 4.7$ & $9.3 \pm 4.9$ & 0.010 \\
\hline Lipid index & $1783.4 \pm 1038.7$ & $1476.0 \pm 1042.7$ & $<0.001$ \\
\hline \multicolumn{4}{|l|}{ OCT qualitative data, $n(\%)$} \\
\hline TCFA & $63(64.9 \%)$ & $13(13.4 \%)$ & $<0.001$ \\
\hline Macrophage & $71(73.2 \%)$ & $58(59.8)$ & 0.019 \\
\hline Micro-vessel & $44(45.4)$ & $29(29.9)$ & 0.004 \\
\hline Cholesterol crystal & $23(23.7)$ & $10(10.3)$ & 0.002 \\
\hline Thrombus & $6(6.2)$ & 0 & N/A \\
\hline Spotty calcification & $25(26.0)$ & $24(24.7)$ & 1.000 \\
\hline Disruption & $9(9.3)$ & 0 & N/A \\
\hline \multicolumn{4}{|l|}{ CAG quantitative data } \\
\hline Minimal lumen diameter, mm & $2.0 \pm 0.5$ & $2.0 \pm 0.5$ & 0.824 \\
\hline Diameter stenosis, $\%$ & $28.9 \pm 10.5$ & $29.5 \pm 11.1$ & 0.530 \\
\hline Lesion length, mm & $11.3 \pm 5.1$ & $11.7 \pm 5.0$ & 0.069 \\
\hline
\end{tabular}

the same period. In addition, the mean lipid length significantly decreased over time (TCFAs: $-1.1 \mathrm{~mm}, p=$ 0.005; ThCFAs: $-0.40 \mathrm{~mm}, p=0.218$ ); however, the mean value of lesion length did not significantly change. Given the above, both TCFAs and ThCFAs showed significant improvements in lesion microstructures, but DS of ThCFAs grew narrower over time; although the lesion length of ThCFAs did not decreased at follow-up, the lipid length inside the lesion was significantly reduced. These results suggested that the lipid core decreased less and diameter stenosis increased in ThCFAs over time.

As shown in Figs. 1 and 2, lipid-rich plaques were also classified according to OCT-derived plaque types, such as the existence of a thin-cap $<65 \mu \mathrm{m}$, macrophage infiltration, microvessels, or cholesterol crystals. The differences between TCFAs and ThCFAs were described above. In addition, no significant differences of crosssectional variables were observed on CAG measurements regardless of whether the lesions contained macrophage infiltration, microvessels, or cholesterol crystals.

\section{Discussion}

To our knowledge, this is the first study to compare coronary lumen dimensions and plaque microstructural characteristics, and their progression during statin therapy using quantitative angiography and OCT imaging. The major results can be summarized as follows: 1) lipid length (OCT) was closely correlated with lesion length (CAG), but the other measurements on OCT and findings on CAG of non-culprit lipid-rich plaques were not significantly correlated; 2) although the microstructures were improved significantly at follow-up, the longitudinal and cross-sectional silhouette of the coronary lesions were not significantly improved; 3 ) compared with TCFAs, ThCFAs had a less decrease in the lipid index; ThCFAs had an increase in diameter stenosis at followup; 4) with 12-month statin therapy, no significant 
Table 3 Correlations between the CAG and OCT data at single time points

\begin{tabular}{|c|c|c|c|}
\hline CAG data & OCT data & Correlation & $p$-value \\
\hline \multicolumn{4}{|l|}{ Baseline } \\
\hline \multirow[t]{5}{*}{ Minimal lumen diameter, mm } & Fibrous-cap thickness, $\mu \mathrm{m}$ & -0.004 & 0.971 \\
\hline & Maximum lipid arc, ${ }^{\circ}$ & 0.062 & 0.545 \\
\hline & Mean lipid arc, ${ }^{\circ}$ & 0.071 & 0.494 \\
\hline & Lipid length, mm & 0.134 & 0.197 \\
\hline & Lipid index & 0.133 & 0.200 \\
\hline \multirow[t]{5}{*}{ Diameter stenosis, \% } & Fibrous-cap thickness, $\mu \mathrm{m}$ & -0.169 & 0.099 \\
\hline & Maximum lipid arc, ${ }^{\circ}$ & 0.209 & 0.041 \\
\hline & Mean lipid arc, ${ }^{\circ}$ & 0.105 & 0.308 \\
\hline & Lipid length, mm & 0.099 & 0.341 \\
\hline & Lipid index & 0.115 & 0.265 \\
\hline \multirow[t]{5}{*}{ Lesion length, mm } & Fibrous-cap thickness, $\mu \mathrm{m}$ & -0.248 & 0.014 \\
\hline & Maximum lipid arc, ${ }^{\circ}$ & -0.303 & 0.003 \\
\hline & Mean lipid $\operatorname{arc}^{\circ}$ & 0.148 & 0.149 \\
\hline & Lipid length, mm & 0.754 & $<0.001$ \\
\hline & Lipid index & 0.648 & $<0.001$ \\
\hline \multicolumn{4}{|l|}{ Follow-up } \\
\hline \multirow[t]{5}{*}{ Minimal lumen diameter, mm } & Fibrous-cap thickness, $\mu \mathrm{m}$ & -0.076 & 0.458 \\
\hline & Maximum lipid arc, ${ }^{\circ}$ & 0.086 & 0.410 \\
\hline & Mean lipid arc, ${ }^{\circ}$ & 0.087 & 0.433 \\
\hline & Lipid length, mm & 0.104 & 0.334 \\
\hline & Lipid index & 0.099 & 0.372 \\
\hline \multirow[t]{5}{*}{ Diameter stenosis, \% } & Fibrous-cap thickness, $\mu \mathrm{m}$ & 0.018 & 0.870 \\
\hline & Maximum lipid arc, ${ }^{\circ}$ & -0.041 & 0.712 \\
\hline & Mean lipid arc, ${ }^{\circ}$ & -0.014 & 0.902 \\
\hline & Lipid length, mm & 0.072 & 0.506 \\
\hline & Lipid index & 0.065 & 0.561 \\
\hline \multirow[t]{5}{*}{ Lesion length, mm } & Fibrous-cap thickness, $\mu \mathrm{m}$ & -0.112 & 0.300 \\
\hline & Maximum lipid arc, ${ }^{\circ}$ & 0.176 & 0.107 \\
\hline & Mean lipid arc, ${ }^{\circ}$ & 0.125 & 0.261 \\
\hline & Lipid length, mm & 0.639 & $<0.001$ \\
\hline & Lipid index & 0.527 & $<0.001$ \\
\hline
\end{tabular}

Correlations between the CAG data and OCT data were analyzed by Pearson or Spearman ranks test. A $p$-value $<0.05$ was considered statistically significant. ${ }^{\circ}$ arc of lipid content. ${ }^{\circ}$ arc of lipid content.

correlations between changes in CAG findings and changes in OCT measurements were observed.

It is generally known that the true architecture of the arterial wall and inside the atherosclerotic cannot be visualized directly using CAG, which is good at depicting the lumen as a longitudinal and cross-sectional silhouette $[15,23]$. OCT, with its high-resolution histological images, has the capacity to delineate microstructural characteristics of atherosclerotic plaques, such as FCT, inflammation, and intra-plaque neovascularization [10, 13, 24]. However, so far, limited researches have been performed to explore correlations between CAG and OCT measurements on coronary atherosclerotic plaque. FCT and lipid burden are incontrovertible crucial factors for the rupture of lipid atherosclerotic plaque [12, 25]. The intravascular modality validated by OCT assessment and histological examination of the fibrous-cap thickness were highly consistent [26], while CAG had limitations to evaluate the microstructures and vulnerability of plaque $[15,24,27]$. Even so, in this study, we found a statistically significant but weak correlation between diameter stenosis by the standard method of evaluating lumen dimension with CAG and the maximum lipid arc with OCT at baseline but not at follow-up. However, if the follow-up duration of statin intervention 
Table 4 Correlations between changes in CAG findings and changes in OCT measurements

\begin{tabular}{|c|c|c|c|}
\hline $\begin{array}{l}\text { Changes in CAG } \\
\text { measurements }\end{array}$ & $\begin{array}{l}\text { Changes in OCT } \\
\text { measurements }\end{array}$ & Correlation & $p$-value \\
\hline \multirow[t]{5}{*}{$\begin{array}{l}\text { Change in minimal } \\
\text { lumen diameter, mm }\end{array}$} & $\begin{array}{l}\text { Change in fibrous-cap } \\
\text { thickness, } \mu \mathrm{m}\end{array}$ & -0.009 & 0.928 \\
\hline & $\begin{array}{l}\text { Change in Maximum } \\
\text { lipid arc, }\end{array}$ & -0.096 & 0.357 \\
\hline & $\begin{array}{l}\text { Change in Mean } \\
\text { lipid } \operatorname{arc}^{\circ}\end{array}$ & -0.079 & 0.440 \\
\hline & $\begin{array}{l}\text { Change in Lipid } \\
\text { length, } \mathrm{mm}\end{array}$ & 0.055 & 0.595 \\
\hline & Change in Lipid index & 0.010 & 0.926 \\
\hline \multirow[t]{5}{*}{$\begin{array}{l}\text { Change in diameter } \\
\text { stenosis, \% }\end{array}$} & $\begin{array}{l}\text { Change in fibrous-cap } \\
\text { thickness, } \mu \mathrm{m}\end{array}$ & 0.085 & 0.409 \\
\hline & $\begin{array}{l}\text { Change in Maximum } \\
\text { lipid } \operatorname{arc}^{\circ}\end{array}$ & 0.157 & 0.130 \\
\hline & $\begin{array}{l}\text { Change in Mean } \\
\text { lipid } \operatorname{arc}^{\circ}\end{array}$ & 0.059 & 0.568 \\
\hline & $\begin{array}{l}\text { Change in Lipid } \\
\text { length, } \mathrm{mm}\end{array}$ & -0.053 & 0.605 \\
\hline & Change in Lipid index & -0.018 & 0.866 \\
\hline \multirow[t]{5}{*}{$\begin{array}{l}\text { Change in lesion } \\
\text { length, } \mathrm{mm}\end{array}$} & $\begin{array}{l}\text { Change in fibrous-cap } \\
\text { thickness, } \mu \mathrm{m}\end{array}$ & -0.119 & 0.247 \\
\hline & $\begin{array}{l}\text { Change in Maximum } \\
\text { lipid } \operatorname{arc}^{\circ}\end{array}$ & -0.081 & 0.436 \\
\hline & $\begin{array}{l}\text { Change in Mean } \\
\text { lipid } \operatorname{arc}^{\circ}\end{array}$ & -0.114 & 0.267 \\
\hline & $\begin{array}{l}\text { Change in Lipid } \\
\text { length, } \mathrm{mm}\end{array}$ & 0.092 & 0.371 \\
\hline & Change in Lipid index & -0.031 & 0.901 \\
\hline
\end{tabular}

is long enough, good correlations might be observed between OCT measurements and CAG findings on coronary plaques.

There were other important discoveries from this study. Lipid length seen on OCT results was strongly correlated with lesion length, but the correlation was weaker after 12 months of statin therapy. The weakened correlation might because statin therapy induces lipid core inside the lesion to shrink; however, lesion length was not significantly reduced at follow-up. In addition, the lipid index and microstructures of the lipid-rich plaques were markedly improved by follow-up time, but the luminal outline seen by CAG were not. These results are consistent with and extend those of previous studies documenting that CAG alone underestimates the composition of atherosclerosis and cannot evaluate the presence and magnitude of plaque microstructure progression [23, 24]. Intravascular OCT provides insights into plaque microstructures, which is needed in lipid-rich plaque progression/regression evaluation.
Table 5 Comparison of TCFAs and ThCFAs at baseline, at follow-up and changes over time

\begin{tabular}{|c|c|c|c|}
\hline & TCFA $(n=63)$ & ThCFA $(n=34)$ & $p$-value \\
\hline \multicolumn{4}{|c|}{ OCT measurements } \\
\hline \multicolumn{4}{|c|}{ Fibrous-cap thickness, $\mu \mathrm{m}$} \\
\hline Baseline & $49.8 \pm 8.3$ & $81.9 \pm 13.4$ & $<0.001$ \\
\hline Follow-up & $144.3 \pm 80.9$ & $186.4 \pm 68.0$ & 0.011 \\
\hline$p$-value & $<0.001$ & $<0.001$ & \\
\hline Change & $94.5 \pm 79.8$ & $104.5 \pm 65.4$ & 0.593 \\
\hline \multicolumn{4}{|c|}{ Maximum lipid arc, ${ }^{\circ}$} \\
\hline Baseline & $261.2 \pm 66.6$ & $204.7 \pm 61.4$ & $<0.001$ \\
\hline Follow-up & $219.4 \pm 74.8$ & $182.8 \pm 71.3$ & 0.022 \\
\hline$p$-value & $<0.001$ & 0.091 & \\
\hline Change & $-41.8 \pm 50.6$ & $-22.0 \pm 45.8$ & 0.060 \\
\hline \multicolumn{4}{|c|}{ Mean lipid arc, ${ }^{\circ}$} \\
\hline Baseline & $190.8 \pm 50.6$ & $145.7 \pm 39.7$ & $<0.001$ \\
\hline Follow-up & $160.6 \pm 56.9$ & $137.6 \pm 50.9$ & 0.052 \\
\hline$p$-value & $<0.001$ & $<0.008$ & \\
\hline Change & $-30.3 \pm 34.6$ & $-8.1 \pm 27.6$ & 0.002 \\
\hline \multicolumn{4}{|c|}{ Lipid length, mm } \\
\hline Baseline & $10.7 \pm 4.9$ & $8.4 \pm 4.0$ & 0.019 \\
\hline Follow-up & $10.4 \pm 5.1$ & $7.3 \pm 3.7$ & 0.003 \\
\hline$p$-value & 0.218 & 0.005 & \\
\hline Change & $-0.4 \pm 2.3$ & $-1.1 \pm 2.0$ & 0.142 \\
\hline \multicolumn{4}{|l|}{ Lipid index } \\
\hline Baseline & $2037.0 \pm 1031.7$ & $1083.6 \pm 630.2$ & $<0.001$ \\
\hline Follow-up & $1727.9 \pm 1108.6$ & $947.0 \pm 705.9$ & $<0.001$ \\
\hline$p$-value & $<0.001$ & 0.007 & \\
\hline Change & $309.1 \pm 494.4$ & $-136.6 \pm 304.7$ & 0.036 \\
\hline
\end{tabular}

\section{CAG measurements}

Minimal lumen diameter, $\mathrm{mm}$

\begin{tabular}{llll} 
Baseline & $2.01 \pm 0.58$ & $1.99 \pm 0.55$ & 0.627 \\
Follow-up & $1.99 \pm 0.55$ & $1.98 \pm 0.53$ & 0.938 \\
$\begin{array}{l}p \text {-value } \\
\text { Change }\end{array}$ & 0.52 & 0.559 & \\
$\begin{array}{l}\text { Diameter stenosis, \% } \\
\text { Baseline }\end{array}$ & $-0.02 \pm 0.28$ & $0.02 \pm 0.24$ & 0.686 \\
Follow-up & $30.7 \pm 10.2$ & $23.8 \pm 9.4$ & 0.021 \\
$\begin{array}{l}p \text {-value } \\
\text { Change }\end{array}$ & $29.5 \pm 10.9$ & $27.7 \pm 10.7$ & 0.878 \\
Lesion length, mm & 0.26 & 0.014 & \\
Baseline & $-1.14 \pm 8.08$ & $3.86 \pm 8.55$ & 0.008 \\
Follow-up & & & \\
$p$-value & $12.3 \pm 5.6$ & $9.37 \pm 3.29$ & 0.001 \\
Change & $12.5 \pm 5.4$ & $9.98 \pm 3.69$ & 0.001 \\
\hline
\end{tabular}

Data are presented as mean \pm SD. Data at baseline and at follow-up are compared using paired $t$ test; data between TCFAs and ThCFAs were compared by using unpaired $t$ test. TCFAs, thin-cap fibroatheromas (FCT $<65 \mu \mathrm{m})$; ThCFAs, thick-cap fibroatheromas (FCT $\geq 65 \mu \mathrm{m}$ ). ${ }^{\circ}$ arc of lipid content. 


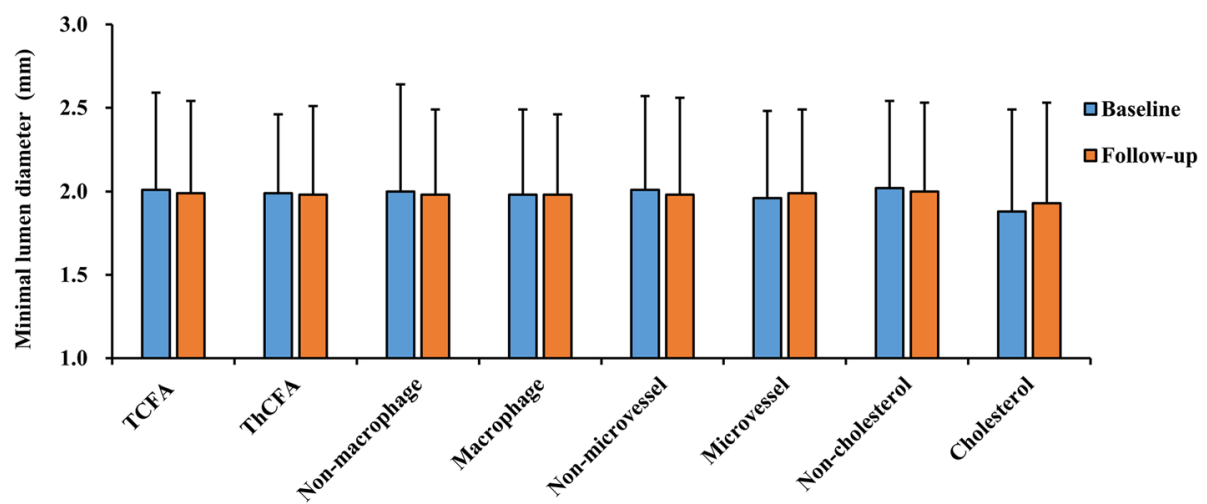

Fig. 1 Comparisons of minimal lumen diameter in terms of OCT-derived plaque type. According to OCT-derived plaque types, plaques were classified into TCFAs and ThCFAs, with or without macrophage, or microvessels, or cholesterol crystals. Minimal lumen diameter showed no significant differences between groups

In the present study, we found that the changes in lumen dimension were not significantly correlated with changes in fibrous-cap thickness, neither with changes in lipid core content. In another analysis on evaluating coronary plaque progression/regression by OCT and IVUS, no significant correlations were found between changes in OCT parameters and changes in IVUS measurements [10].

The 12-month statin treatment has been reported to induce lipid-rich plaque stabilization, such as continuously thickening the fibrous cap and decreasing the presence of macrophage infiltration; however, the plaque volume determined by intravascular ultrasonography (IVUS) was not reduced [5], and the cross-sectional lumen architecture of coronary lesions were not significantly improved. This is most likely because statin induces fibrouscap thickness of vulnerable plaques increasing, but the lipid core under the fibrous cap shrinking. Significant changes in atheroma volume and lumen dimensions cannot be discovered if follow-up time or the duration of statin treatment is too short. Results of SATURN trial using IVUS showed that maximal doses of statin-based lipid- lowering treatment for 104 weeks induced regression of atheroma volume [6]. Accordingly, the reduced vulnerability of lipid-rich plaques most likely occurs earlier than improvements in plaque volume and lumen dimensions during statin therapy; therefore, perennial statin-based lipid-modulating therapy and a long-term follow-up are necessary to attain the benefits of statins on decreased plaque volume and improved diameter stenosis.

OCT-derived TCFAs have been recognized as distinguishing features of so-called vulnerable or ruptureprone plaques [28]. Compared with TCFAs, ThCFAs had less of a decrease in the lipid index, but had an increase in diameter stenosis by follow-up period. The increase of fibrous-cap thickness in ThCFAs was not significantly different to that in TCFAs, while the decrease in lipid core burden of ThCFAs was much smaller than that of TCFAs. These findings might contribute to the differences between them in the changes in diameter stenosis, and lumen dimensions, which are most likely one process of statin-induced regression of ThCFAs; however, the present study was conducted for only 12 months. It

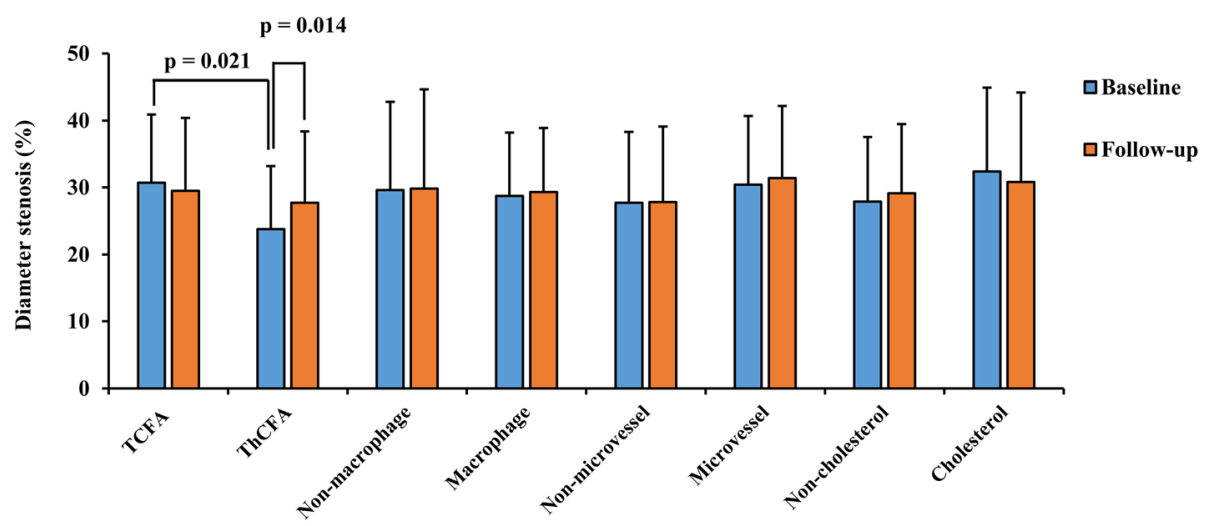

Fig. 2 Comparisons of diameter stenosis in terms of OCT-derived plaque type. At baseline, diameter stenosis were significantly worse in TCFAs ( $p=0.021$ ). To compare the data at baseline and at follow-up in ThCFAs, we found that diameter stenosis was growing worse at follow-up ( $p=0.014)$ 
remains unknown whether diameter stenosis of ThCFAs would improve with a longer-term follow-up.

\section{Limitations}

First, it was inevitable that the retrospective study from a clinical registry introduced a potential selection bias. Second, because of the short duration and small size of population of our study, the changes in CAG data did not correlated with the changes in OCT measurements. Additional studies with larger populations and longer term follow-up might be needed. Third, the definition of OCT-derived TCFAs does not correspond exactly with the histological definition of TCFAs because OCT cannot measure the necrotic core size; the macrophage infiltration, micro-vessels, cholesterol crystals, thrombus, calcification, and disruption were not quantified in the present study. Finally, the general results of nonculprit, lipid-rich plaques in this study cannot be applied to other types of plaques.

\section{Conclusion}

We found that the lipid length on OCT and the lesion length on CAG of lipid-rich plaques were closely correlated; however, the other microstructural characteristics measured by OCT and lumen dimensions by CAG were not significantly correlated. After 12-month statin treatment, we observed that microstructural characteristics measured were significantly improved, while CAGderived lumen dimensions were not. Moreover, changes in OCT measurements were not significantly correlated with changes in CAG data induced by statin over time.

\section{Abbreviations \\ CAG: Coronary angiography; DS: Diameter stenosis; HDL-C: High-density lipoprotein cholesterol; LDL-C: Low-density lipoprotein cholesterol; MLD: Minimal lumen diameter; OCT: Optical coherence tomography; TCFAs: Thin-cap fibroatheromas; ThCFAs: Thick-cap fibroatheromas}

\section{Acknowledgement}

None.

\section{Funding}

This was a retrospective study of a single blind and randomized clinical trial registry (ClinicalTrial.gov registered number: NCT01023607). This study has received research grants from National Natural Science Foundation (CN 81330033), Top-Notch Young Talents Program, Open Foundation in China's Ministry of Education (KF201401) of China, and Graduate Student Innovation Foundation of Heilongjiang Province, China (YJSCX2012-217HLJ).

\section{Availability of data and materials}

All details of this registration were shown in ClinicalTrial.gov, with the Identifier: NCT01023607. The datasets supporting the findings of this article are included within the article and available in the Supplementary Materials.

\section{Authors' contributions}

All authors were involved in reporting the results of this study. YB and TJ made substantial contributions to conception, design and planning of the study. DJ, XZ, WW and Zhongyue Pu conducted the study and were involved in recruiting patients and keeping the patient database. DN and SM participated in interpretation of data and statistical analyses. Manuscript writing: YB and DN. $\mathrm{YB}$ is responsible for the overall content and serves as guarantor. All authors read and approved the final version of the submitted manuscript.

\section{Competing interests}

All of the authors declare they have no competing interests.

Consent for publication

There is no individual participant's data in any form (including images, videos, voice recordings etc.).

Ethics approval and consent to participate

This study was approved by the institutional review board of the Second Hospital of Harbin Medical University (Harbin, China). All patients provided written informed consent before any procedures were initiated.

\section{Author details}

${ }^{1}$ Department of Cardiology, 2nd Affiliated Hospital of Harbin Medical University, 246 Xuefu Road, Nangang District, Harbin 150086, China. ${ }^{2}$ Key Laboratory of Myocardial Ischemia, Harbin Medical University, Ministry of Education, 246 Xuefu Road, Nangang District, Harbin 150086, China.

Received: 8 June 2016 Accepted: 7 November 2016

Published online: 22 November 2016

\section{References}

1. Fuster V, Fayad ZA, Badimon JJ. Acute coronary syndromes: biology. Lancet. 1999;353 Suppl 2:SII5-9.

2. Toschi V, Gallo R, Lettino M, Fallon JT, Gertz SD, Fernandez-Ortiz A, et al. Tissue factor modulates the thrombogenicity of human atherosclerotic plaques. Circulation. 1997;95:594-9.

3. Tian J, Dauerman H, Toma C, Samady H, Itoh T, Kuramitsu S, et al. Prevalence and characteristics of TCFA and degree of coronary artery stenosis: an OCT, IVUS, and angiographic study. J Am Coll Cardiol. 2014;64:672-80.

4. Yonetsu T, Bouma BE, Kato K, Fujimoto JG, Jang IK. Optical coherence tomography- 15 years in cardiology. Circ J. 2013;77:1933-40.

5. Hou J, Xing L, Jia H, Vergallo R, Soeda T, Minami $Y$, et al. Comparison of Intensive Versus Moderate Lipid-Lowering Therapy on Fibrous Cap and Atheroma Volume of Coronary Lipid-Rich Plaque Using Serial Optical Coherence Tomography and Intravascular Ultrasound Imaging. Am J Cardiol. 2016;117:800-6.

6. Nicholls SJ, Ballantyne CM, Barter PJ, Chapman MJ, Erbel RM, Libby P, et al. Effect of two intensive statin regimens on progression of coronary disease. N Engl J Med. 2011;365:2078-87.

7. Goh VK, Lau CP, Mohlenkamp S, Rumberger JA, Achenbach S, Budoff MJ. Outcome of coronary plaque burden: a 10-year follow-up of aggressive medical management. Cardiovasc Ultrasound. 2010;8:5.

8. Kubo T, Imanishi T, Takarada S, Kuroi A, Ueno S, Yamano T, et al. Assessment of culprit lesion morphology in acute myocardial infarction: ability of optical coherence tomography compared with intravascular ultrasound and coronary angioscopy. J Am Coll Cardiol. 2007:50:933-9.

9. Toutouzas K, Stathogiannis K, Synetos A, Karanasos A, Stefanadis C. Vulnerable atherosclerotic plaque: from the basic research laboratory to the clinic. Cardiology. 2012;123:248-53.

10. Xie Z, Tian J, Ma L, Du H, Dong N, et al. Comparison of optical coherence tomography and intravascular ultrasound for evaluation of coronary lipidrich atherosclerotic plaque progression and regression. Eur Heart J Cardiovasc Imaging. 2015;16:1374-80.

11. Huang D, Swanson EA, Lin CP, Schuman JS, Stinson WG, Chang W, et al. Optical coherence tomography. Science. 1991;254:1178-81.

12. Virmani R, Kolodgie FD, Burke AP, Farb A, Schwartz SM. Lessons from sudden coronary death: a comprehensive morphological classification scheme for atherosclerotic lesions. Arterioscler Thrombosis Vasc Biol. 2000; 20:1262-75

13. Jang IK, Bouma BE, Kang DH, Park SJ, Park SW, Seung KB, et al. Visualization of coronary atherosclerotic plaques in patients using optical coherence tomography: comparison with intravascular ultrasound. J Am Coll Cardiol. 2002;20(39):604-9

14. Kan J, Gao X, Sandeep KG, Xu H, Zhao Y, Chen S, et al. Comparison of two and three dimensional quantitative coronary angiography to intravascular ultrasound in the assessment of left main coronary artery bifurcation lesions. Chin Med J (Engl). 2014;127:1012-21.

15. Feld S, Ganim M, Carell ES, Kjellgren O, Kirkeeide RL, Vaughn WK, et al. Comparison of angioscopy, intravascular ultrasound imaging and quantitative 
coronary angiography in predicting clinical outcome after coronary intervention in high risk patients. J Am Coll Cardioly. 1996;28:97-105.

16. van Velzen JE, de Graaf FR, Jukema JW, de Grooth GJ, Pundziute G, Kroft LJ, et al. Comparison of the relation between the calcium score and plaque characteristics in patients with acute coronary syndrome versus patients with stable coronary artery disease, assessed by computed tomography angiography and virtual histology intravascular ultrasound. Am J Cardiol. 2011;108:658-64

17. Otaki M. Percutaneous transradial approach for coronary angiography. Cardiology. 1992;81:330-3.

18. Kato K, Yonetsu T, Kim SJ, Xing L, Lee H, McNulty I, Yeh RW, et al. Comparison of nonculprit coronary plaque characteristics between patients with and without diabetes: a 3-vessel optical coherence tomography study. JACC Cardiovasc interv. 2012;5:1150-8.

19. Jin $\mathrm{QH}$, Chen YD, Jing J, Tian F, Guo J, Liu CF, et al. Incidence, predictors, and clinical impact of tissue prolapse after coronary intervention: an intravascular optical coherence tomography study. Cardiology. 2011;119:197-203.

20. Lee SJ, Kim BK, Kim JS, Ko YG, Choi D, Jang Y, et al. Evaluation of neointimal morphology of lesions with or without in-stent restenosis: an optical coherence tomography study. Clin Cardiol. 2011;34:633-9.

21. Tearney GJ, Waxman S, Shishkov M, Vakoc BJ, Suter MJ, Freilich MI, et al. Three-dimensional coronary artery microscopy by intracoronary optical frequency domain imaging. JACC Cardiovasc Imaging. 2008;1:752-61.

22. Takano M, Yamamoto M, Seino Y, Mizuno K. Thrombus in sirolimus-eluting stent identified by optical coherence tomography. Clin Cardiol. 2010;33, E60.

23. Hanson ID, Goldstein JA, Dixon SR, Stone GW. Comparison of coronary artery lesion length by NIRS-IVUS versus angiography alone. Coron Artery Dis. 2015;26:484-9.

24. Pundziute G, Schuijf JD, Jukema JW, Boersma E, de Roos A, van der Wall EE, et al. Prognostic value of multislice computed tomography coronary angiography in patients with known or suspected coronary artery disease. J Am Coll Cardiol. 2007:49:62-70.

25. Virmani R, Burke A, Farb A. Coronary risk factors and plaque morphology in men with coronary disease who died suddenly. Eur Heart J. 1998;19:678-80.

26. Kume T, Akasaka T, Kawamoto T, Okura H, Watanabe N, Toyota E, et al. Measurement of the thickness of the fibrous cap by optical coherence tomography. Am Heart J. 2006;152:755. e1-4.

27. Sato A, Aonuma K. Role of cardiac multidetector computed tomography beyond coronary angiography. Circ J. 2015;79:712-20.

28. Uemura S, Ishigami K, Soeda T, Okayama S, Sung JH, Nakagawa H, et al. Thin-cap fibroatheroma and microchannel findings in optical coherence tomography correlate with subsequent progression of coronary atheromatous plaques. Eur Heart J. 2012;33:78-85.

\section{Submit your next manuscript to BioMed Central and we will help you at every step:}

- We accept pre-submission inquiries

- Our selector tool helps you to find the most relevant journal

- We provide round the clock customer support

- Convenient online submission

- Thorough peer review

- Inclusion in PubMed and all major indexing services

- Maximum visibility for your research

Submit your manuscript at www.biomedcentral.com/submit

C Biomed Central 